
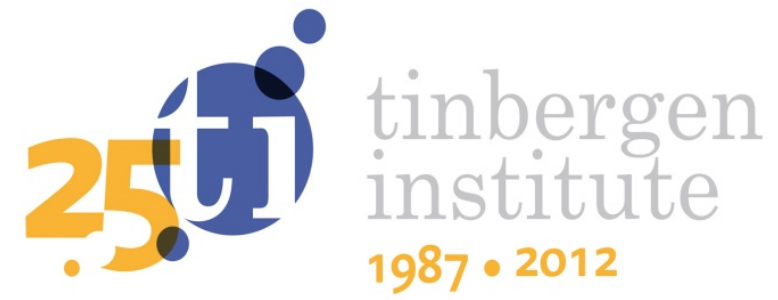

\title{
Structural Change and Convergence of Energy Intensity across OECD countries, 1970-2005
}

Peter Mulder

Henri L.F. de Groot*

Faculty of Economics and Business Administration, VU University Amsterdam.

* Tinbergen Institute. 
Tinbergen Institute is the graduate school and research institute in economics of Erasmus University Rotterdam, the University of Amsterdam and VU University Amsterdam.

More TI discussion papers can be downloaded at http://www.tinbergen.nl

Tinbergen Institute has two locations:

Tinbergen Institute Amsterdam

Gustav Mahlerplein 117

1082 MS Amsterdam

The Netherlands

Tel.: +31(0)205251600

Tinbergen Institute Rotterdam

Burg. Oudlaan 50

3062 PA Rotterdam

The Netherlands

Tel.: +31(0)10 4088900

Fax: $+31(0) 104089031$

Duisenberg school of finance is a collaboration of the Dutch financial sector and universities, with the ambition to support innovative research and offer top quality academic education in core areas of finance.

DSF research papers can be downloaded at: http://www.dsf.nl/

Duisenberg school of finance

Gustav Mahlerplein 117

1082 MS Amsterdam

The Netherlands

Tel.: +31(0)20 5258579 


\title{
Structural Change and Convergence of Energy Intensity across OECD Countries, 1970-2005
}

\author{
Peter Mulder and Henri L.F. de Groot* \\ Dept. of Spatial Economics, VU University Amsterdam \\ De Boelelaan 1105, 1081 HV Amsterdam, The Netherlands
}

\begin{abstract}
This paper uses a new dataset derived from a consistent framework of national accounts to compute and evaluate energy intensity developments across 18 OECD countries and 50 sectors over the period 1970-2005. We find that across countries energy intensity levels tend to increase in a fairly wide range of Services subsectors, but decrease in most Manufacturing sectors. A decomposition analysis reveals that changes in the sectoral composition of the economy explain a considerable and increasing part of aggregate energy intensity dynamics. A convergence analysis reveals that only after 1995 cross-country variation in aggregate energy intensity levels clearly tends to decrease, driven by a strong and robust trend break in Manufacturing and enhanced convergence in Services. Moreover, we find evidence for the hypothesis that across sectors lagging countries are catching-up with leading countries, with rates of convergence on average being higher in Services than in Manufacturing. Aggregate convergence patterns are almost exclusively caused by convergence of within-sector energy intensity levels, and not by convergence of the sectoral composition of economies.
\end{abstract}

Keywords: $\quad$ Energy Intensity, Convergence, Decomposition, Sectoral Analysis

JEL codes: $\quad$ O13, O47, O5, Q43

\footnotetext{
* Corresponding author: Peter Mulder, E-mail: p.mulder@vu.nl. Henri de Groot is also affiliated to Tinbergen Institute (Amsterdam-Rotterdam) and Ecorys NEI (Rotterdam). This paper results from the research project 'Environmental Policy and Economics' initiated by the Dutch Ministry of Economic Affairs. Excellent research assistance was provided by Adriaan van Hien. The authors gratefully acknowledge useful comments on earlier versions by Rob Aalbers, Hillard Huntington, Casper van Ewijk, Paul Koutstaal, and Marcel Timmer, as well as participants of the WIOD Conference (Vienna, 2010) and the International Energy Workshop (Stockholm, 2010). The authors alone are responsible for the views expressed and for any errors or omissions that remain.
} 


\section{Introduction}

Accurate projections of future energy demand and greenhouse gas emissions require careful evaluation of historical trends in the relationship between energy use and economic activity. In this paper we present new empirical evidence on this relationship for the period 1970-2005. We do so by analyzing and comparing the development of energy intensity (i.e. the ratio of energy input to economic output) across 50 sectors and 18 OECD countries. More specifically, our analysis comprises 25 Manufacturing sectors (10 main sectors, 15 subsectors), 23 Services sectors (9 main sectors, 14 subsectors), as well as the sectors Agriculture and Construction; it includes 16 EU member countries, the USA, Japan and South Korea.

Distinctive features of our analysis are its combination of a cross-country perspective with a high level of sectoral detail, the inclusion of a wide range of Service sectors and the quality of our dataset. Regarding the latter, we make use of the recently launched 'EU KLEMS Growth and Productivity Accounts' database, which we link to physical energy data from the International Energy Agency (IEA). The EU KLEMS database (O'Mahony and Timmer 2009) contains industry-level measures of output, inputs and productivity as well as information on energy inputs, derived from a consistent framework of national accounts and supply-and-use tables and processed according to agreed procedures. Consequently, in contrast to most existing empirical cross-country studies on the energy-economy nexus (see, for example, Markandya et al. 2006, Miketa 2001, Miketa and Mulder 2005, Mulder and De Groot 2007, Nilsson 1993, Schipper et al. 2001, Smulders and De Nooij 2003), we do not rely on study-specific ad hoc combinations of energy input and economic output measures from different sources - thus avoiding problems in defining sectors consistently across energy and economic variables and facilitating comparability of results across countries. Another major advantage of the EU KLEMS database is that it moves beneath the aggregate economy level by providing a breakdown of industries to a common detailed level. Typically, cross-country studies of productivity and growth come at the price of limited sectoral detail. This is a serious drawback, given the existence of substantial heterogeneity in output and productivity growth across industries (see, for example, Florax et al. 2011, Huntington 2010, Jorgenson 1984, Mulder 2005). To the best of our knowledge, we are the first to use the 'EU KLEMS Growth and Productivity Accounts' database in the field of energy studies.

More specifically, our analysis includes the following components. First, we document per country the growth rates of energy intensity (i.e. the ratio of energy use to value added) at various levels of aggregation. Second, by means of a decomposition analysis we calculate for each country to what extent aggregate energy intensity trends are to be explained from, respectively, shifts in the underlying sectoral structure and efficiency improvements within individual sectors. Third, across sectors we analyze the evolution of the observed cross-countries differences over time, documenting and decomposing patterns of cross-country convergence of energy intensity levels. 
The first part of our analysis is closely related to numerous empirical studies documenting trends in energy use, energy intensity and emission intensity (see, for example, Berndt 1978, Neelis et al. 2007, Nilsson 1993, Sue Wing 2008, Schipper et al. 2001, Worell 2004). The second part of our analysis fits in the research area known as index number decomposition analysis (see Ang and Zhang 2000 and Liu and Ang 2007 for recent surveys). The final part of our analysis relates to recent work on cross-country convergence of energy- or emission intensities (see, for example, Aldy 2006, Jakob et al. 2012, Liddle 2009, Markandya et al. 2006, Miketa and Mulder 2005, Mulder and De Groot 2007, Romero-Avila 2008, Sun 2002) and extends the decomposition approach developed by Wong (2006).

It is the objective of this study to contribute new figures and insights to these literatures. The main novelty of our approach is that we explore a unique combination of a cross-country perspective and high level of sectoral detail. Decomposition studies that include a high level of sector detail are usually limited in scope oftentimes focusing on a single country (see, for example, Fisher-Vanden et al. 2004, Huntington 2010, Ma and Stern 2008, Mairet and Decellas 2009, Sue Wing 2008). Conversely, decomposition studies that include a cross-country perspective are usually limited in terms of sector detail, and often tend to focus on the Manufacturing sector with an emphasis on heavy industries (see, for example, Eichhammer and Mansbart 1997, Fisher-Vanden et al. 2004, Howarth et al. 1991, Lescaroux 2008, Unander et al. 1999, Unander, F. 2007, Park et al. 1993). ${ }^{1}$ In these studies, a limited degree of sectoral disaggregation may lead to biased results as it may obscure shifts from energy intensive to energy extensive subsectors, which consequently will show up as efficiency improvements. Similarly, studies on cross-country convergence of energy use or energy intensity often include no or limited sector detail (see, for example, Duro and Padilla 2011, Jakob et al. 2012, Liddle 2009, Sun 2002). In contrast, in all aspects of our cross-country study, we explore a high level of sector heterogeneity that is not limited to Manufacturing or heavy industry but also includes a range of service sectors and energy-extensive industries. Consequently, we are able to provide for a range of countries detailed evidence on which sectors drive trends in aggregate energy intensity across the entire economy. In addition - unlike many previous studies that analyze trends in energy intensity or energy productivity - we use a common data source on energy and economic activities. As a result, we (largely) avoid problems in defining sectors consistently across energy and economic variables. This is important because - although seldom explicitly acknowledged - inconsistent sector definitions may cause large errors despite the use of the most precise index-number procedure (Huntington 2010). To facilitate an evaluation of the value of using the EU KLEMS framework in the field of energy economics we compare our results with evidence derived from the widely used combination of the OECD Structural Analysis (STAN) database (economy

\footnotetext{
${ }^{1}$ An exception is Mulder and De Groot (2011), who present a decomposition analysis across 14 OECD countries, including energy-extensive sectors such as light industries.
} 
data) with IEA energy data (see, for example, Mulder and De Groot 2007 and Smulders and De Nooij 2003 for applications with those data).

The results in this paper reveal that across countries energy intensity levels tend to increase in a fairly wide range of Services subsectors, but decrease in most Manufacturing sectors. A decomposition analysis shows that changes in the sectoral composition of the economy explain a considerable and increasing part of aggregate energy intensity patterns. A convergence analysis reveals that only after 1995 cross-country variation in aggregate energy intensity levels clearly tends to decrease, driven by a strong and robust trend break in Manufacturing and enhanced convergence in Services. Moreover, we find evidence for the hypothesis that across sectors lagging countries are catching-up with leading countries, with rates of convergence on average being higher in Services than in Manufacturing. Aggregate convergence patterns are almost exclusively caused by convergence of within-sector energy intensity levels, and not by convergence of the sectoral composition of economies.

The paper proceeds as follows. In Section 2 we further introduce and discuss our database. In Section 3 we present new cross-country evidence on energy intensity growth rates at various levels of aggregation, and compare this with evidence from IEA/STAN data. In Section 4 we present the result of our index number decomposition analysis, identifying the role of structural shifts and efficiency improvements in explaining energy intensity trends at various levels of aggregation. In Section 5 we present the results of our convergence analysis. Section 6 concludes and discusses directions for future research that may benefit from the integrated EU KLEMS - IEA database.

\section{Data}

The dataset we use in this study combines the EU KLEMS database (March 2008 release) with energy data from the International Energy Agency (IEA). The database includes measures of output and input growth as well as derived variables such as multi-factor productivity, organized around the growth accounting methodology rooted in neoclassical production theory. In addition, the database provides many basic input data-series that are derived independently from the assumptions underlying the growthaccounting method, including various categories of capital, labor, energy and material. The database has been constructed on the basis of data delivered by EU KLEMS consortium partners with cooperation of national statistical offices, and processed according to agreed procedures. The approach taken follows a two-step procedure. First, the most recent and revised series by industry on gross output, value added and total intermediate input were taken from National Accounts. These series are extended and broken down 
into more industry-detail if needed. In a second step total intermediate inputs were broken down into energy, materials and services based on supply-and-use tables. ${ }^{2}$

We measure energy intensity by the ratio of intermediate energy input to gross value added, viz. the inverse of energy productivity. Value added data have been converted to constant 1997 US\$, using a new and comprehensive dataset of industry-specific Purchasing Power Parities (PPPs) for 1997. These PPP series were constructed in the EU KLEMS project by double deflation of gross output and intermediate inputs within a consistent input-output framework. The price concepts for gross output (basic prices) and intermediate inputs (purchasing prices) have been harmonized across countries. As these series are often short (as revisions are not always taken back in time) different vintages of the National Accounts were bridged according to a common link methodology. The energy data consist of expenditure based intermediate inputs that encompass all energy mining products, oil refining products and electricity and gas products. Using detailed supply-and-use tables, energy expenditures at the industry-level have been deflated by the relative price index of each fuel (energy carrier). As mentioned before, this implies that the intermediate energy input series and value added series are mutually consistent. Hence, to construct a value added based energy intensity indicator one does no longer need to rely on different sources, with its inherent complications.

The intermediate energy data series in EU KLEMS are provided in terms of volume indices only. Consequently, the original EU KLEMS database itself allows calculating energy intensity growth rates but not energy input levels across countries and across sectors. For this reason we enriched the EU KLEMS database by establishing a link with physical energy data from the IEA, according to the following simple two-step procedure. First, for the year 2005 we matched the EU KLEMS energy volume index number with IEA final energy consumption data in kilo tonnes of oil equivalents (ktoe). Second, we used the EU KLEMS energy input volume indices to (re-)calculate energy consumption in ktoe back in time. Guided by the sectoral classification that the IEA uses in its Energy Balances, the first step could be done straightforwardly for 10 Manufacturing sectors as well as the aggregate Service, Transport, Agriculture and Construction sectors. For the remaining sub-sectors, we applied proportions of subsectoral intermediate energy input expenditures (at purchasing prices), as given in EU KLEMS, to IEA final energy consumption data at the aggregate sector level, again for the year 2005. This procedure rests on the assumption that in 2005 average energy prices within a specific industry are identical across subsectors. This would require the same fuel price levels as well as the same fuel mix across subsectors within an industry. This requirement is met in all Service sectors (that almost exclusively consume

\footnotetext{
${ }^{2}$ For a more detailed description and discussion of the EU KLEMS database we refer to (O'Mahony and Timmer 2009). In addition, methodological background papers are available at the EU KLEMS website (www.euklems.net). The EU KLEMS data series are also publicly available at this website.
} 
electricity) as well as in most Manufacturing sectors, except for the aggregate sector Non-Specified Industry. Hence, the energy level data (not the growth rates) for this industry require careful interpretation as - depending on the country - they might suffer from some degree of bias, predominantly due to differences in fuel mix across its subsectors. In general, it has to be borne in mind that our data do not allow to account for the role of fuel input mix in driving aggregate energy intensity developments since the EU KLEMS database only provides volume indices of aggregate intermediate energy inputs, defined as an expenditure based aggregate of all energy carriers.

As mentioned before, a key feature of the EU KLEMS cross-country database is its high level of sector-detail. At the lowest level of aggregation, the EU KLEMS database includes 71 sectors (NACE revision 1 classification). Limited availability of the energy input measure, however, allows us to distinguish 'only' 50 sectors in order to ensure international comparability of the data. This industry division is considerably more detailed than the 2-digit level that has been used so far in most crosscountry energy intensity analyses, which is particularly relevant for properly separating the role of efficiency effects from sectoral composition effects in driving aggregate intensity developments. Nevertheless, when using this data in the field of energy economics three caveats are to be borne in mind. First, the Chemicals sector combines the energy-intensive sub-sector Basic Industrial Chemicals and the energy-extensive sub-sector Pharmaceuticals. Although EU KLEMS provides a breakdown at the lowest level of aggregation, limited data availability allowed us to only include the 2-digit industry level in order to secure comparison across countries. Second, the Basic Metals sector is an aggregate of the subsector Non-Ferrous Metals and the sub-sector Iron and Steel. Here, EU KLEMS does not provide a further breakdown - making it the only sector with less industry detail than previously available (see, for example, Mulder and De Groot 2007). Third, the focus of EU KLEMS on productive sectors precludes the analysis of households and the personal transport sector, since they predominantly involve non-market activities that are excluded from National Accounts. In short, our dataset deals with non-residential energy use. ${ }^{3}$

In terms of country coverage, our dataset includes the following 18 countries: 11 EU-15 countries (Austria, Belgium, Denmark, Finland, France, Germany, Italy, the Netherlands, Spain, Sweden and the United Kingdom), 4 new EU-member states (Czech Republic, Hungary, Poland, Slovakia), the USA, Japan and South Korea. To ensure comparability of data across countries, in our analysis we

\footnotetext{
3 We also exclude the commercial transport sector, because of difficulties in linking the EU KLEMS and IEA energy data for this sector. Value added data in the EU KLEMS dataset refer to carrier (commercial) transportation and do not include personal transportation, since the latter is not part of National Accounts. IEA transport data cover all transport activity (in mobile engines) - including aviation, road, rail and domestic navigation - regardless of the economic sector to which it is contributing. It also includes household demand for transport fuels while for many countries the domestic/international split in aviation fuel data incorrectly excludes fuel used by domestically owned carriers for their international departures.
} 
distinguish the periods 1970-2005, 1980-1995 and 1995-2005 and cluster countries in three groups: OECD-18 (all countries), EU-10 ('Western Europe'; the 11 EU-15 countries minus Italy, because of data limitations), and EU-4 ('Eastern Europe'; the aforementioned 4 transition countries). ${ }^{4}$

\section{Trends}

This section presents new evidence on the evolution of energy intensity across countries at different levels of aggregation. To facilitate evaluation of our data, we also provide a comparison with energy intensity indicators derived from the widely used combination of IEA and STAN data. Key results are presented in Table 1. Because of space limitations, we limit ourselves to highlight the main findings. First, in most countries growth in value added outpaces growth in energy use, resulting in decreasing energy intensity levels. Second, the Construction and Services sectors are special cases: in contrast with the rest of the economy, in these sectors we find evidence of increasing energy intensity levels across a range of OECD countries and different time periods. Third, changes in energy intensity differ substantially across countries and sectors. Fourth, in the EU-4 (Eastern Europe) region energy intensity levels decrease relatively fast, suggesting evidence of an 'advantage of backwardness' (Gerschenkron 1952, Abramovitz 1986): the transformation towards relatively energy-intensive structures in the communistic era apparently carries a potential for rapid advance in the period thereafter (cf. Cornillie and Fankhauser 2004, Markandya et al. 2006). We return to this catching-up hypothesis in Section 5. Fifth, in the USA and the EU-10 region (Western Europe), manufacturing energy intensity levels decreased relatively fast after 1995, especially in the USA. Underlying data indeed reveal a remarkable slowdown in energy intensity decrease between 1980 and 1995 across the relevant countries. This trend has not gone unnoticed in the literature and is linked to the relatively low and decreasing energy prices since the mid1980s, after a period of high prices induced by the energy crises of the 1970s and subsequent energy efficiency improvements (IEA 2004). Table 1, as well as underlying data, show that Services, Agriculture and Construction display an opposite trend: for a range of OECD countries in those sectors energy intensity decreased relatively rapid in the period 1980-1995, and decreased considerably less thereafter. ${ }^{5}$

\footnotetext{
${ }^{4}$ The original EU KLEMS database also includes Australia, Cyprus, Estonia, Greece, Ireland, Latvia, Lithuania, Luxembourg, Malta, Portugal and Slovenia. Limited data availability made us decide to not include these countries in this study. More details are available in Appendix A, Table A.1.

${ }^{5}$ Table A.3 in Appendix A presents supplementary country-specific data, differentiated for the periods 1980-2005, 1980-1995 and 1995-2005.
} 
Table 1. Average annual growth rates energy intensity per main sector

\begin{tabular}{|c|c|c|c|c|c|c|c|}
\hline & \multicolumn{4}{|c|}{$\begin{array}{l}\text { Average annual growth rate of } \\
\text { energy intensity }\end{array}$} & \multirow{2}{*}{\multicolumn{3}{|c|}{$\begin{array}{c}\begin{array}{c}\text { Energy intensity growth } \\
\text { differentials between EUK } \\
\text { and IEA/STAN }\end{array} \\
1995-2005\end{array}$}} \\
\hline & \multirow{2}{*}{$\begin{array}{r}\text { 1970-2005 } \\
\text { EUK }\end{array}$} & \multirow{2}{*}{$\begin{array}{r}\text { 1980-2005 } \\
\text { EUK }\end{array}$} & \multirow{2}{*}{$\begin{array}{r}\text { 1995-2005 } \\
\text { EUK }\end{array}$} & \multirow{2}{*}{$\begin{array}{c}\text { 1995-2005 } \\
\text { IEA/STAN }\end{array}$} & & & \\
\hline & & & & & $E / Y$ & $E$ & $Y$ \\
\hline & [1] & [2] & [3] & [4] & {$[3]-[4]^{*}$} & [5] & [6] \\
\hline \multicolumn{8}{|l|}{ Total } \\
\hline USA & -2.5 & -3.2 & -4.1 & -1.9 & -2.2 & -1.5 & 0.6 \\
\hline Japan & & -1.0 & -1.0 & & & & 0.5 \\
\hline EU-10 & & -1.7 & -1.7 & -1.1 & -0.6 & -0.4 & 0.1 \\
\hline EU-4 & & & -2.6 & -4.9 & 2.2 & 2.7 & 0.5 \\
\hline OECD-18 & & & -2.6 & -1.5 & -1.1 & -0.6 & 0.4 \\
\hline \multicolumn{8}{|l|}{ Manufacturing } \\
\hline USA & -2.9 & -3.7 & -6.4 & -0.7 & -5.6 & -2.8 & 2.8 \\
\hline Japan & & -2.5 & -2.5 & & & & 0.8 \\
\hline EU-10 & & -1.3 & -1.5 & -0.4 & -1.1 & -0.9 & 0.1 \\
\hline EU-4 & & & -5.2 & -8.3 & 3.1 & 4.7 & 1.6 \\
\hline OECD-18 & & & -3.7 & -0.6 & -3.1 & -1.3 & 1.8 \\
\hline \multicolumn{8}{|l|}{ Services } \\
\hline USA & -1.7 & -1.8 & -1.3 & -1.8 & 0.4 & 0.6 & 0.2 \\
\hline Japan & & 1.8 & 0.8 & 0.7 & 0.1 & 0.4 & 0.3 \\
\hline EU-10 & & -1.3 & -0.6 & -1.4 & 0.8 & 0.9 & 0.1 \\
\hline EU-4 & & & -2.4 & -1.1 & -1.3 & -1.0 & 0.3 \\
\hline OECD-18 & & & -1.5 & -1.4 & -0.1 & -0.1 & 0.0 \\
\hline \multicolumn{8}{|l|}{ Agriculture } \\
\hline USA & -3.0 & -5.3 & -2.3 & -3.9 & 1.6 & 0.2 & -1.4 \\
\hline Japan & & 0.9 & -0.4 & 0.7 & -1.1 & -1.7 & -0.6 \\
\hline EU-10 & & -2.3 & -1.7 & -0.9 & -0.8 & -0.7 & 0.1 \\
\hline EU-4 & & & -4.4 & -4.3 & -0.1 & 0.1 & 0.1 \\
\hline OECD-18 & & & -2.8 & -2.6 & -0.2 & -0.5 & -0.2 \\
\hline \multicolumn{8}{|l|}{ Construction } \\
\hline USA & 0.7 & 0.6 & 0.8 & 5.8 & -5.0 & -5.0 & 0.0 \\
\hline Japan & & 1.9 & 3.3 & -1.0 & 4.3 & 4.3 & 0.0 \\
\hline EU-10 & & -1.9 & -1.3 & 0.7 & -2.0 & -2.1 & -0.2 \\
\hline EU-4 & & & -1.9 & -8.7 & 6.9 & 7.2 & 0.3 \\
\hline OECD-18 & & & 0.0 & -1.6 & 1.6 & 0.8 & -0.7 \\
\hline
\end{tabular}

$*[3]-[4]=[5]-[6]$ 
In addition, Table 1 reveals that the use of EU KLEMS or IEA/STAN data leads to considerably different energy intensity rates, particularly in Manufacturing. ${ }^{6}$ It can be seen that this is mainly caused by differences in energy use data between the two sources, although in some countries value added data also differ sizably, again especially in Manufacturing. ${ }^{7}$ Two issues explain the observed differences in value added series between the two data sources. First, STAN makes use of aggregate country-specific PPP's, whereas in EU KLEMS PPP's have been constructed at the industry-level - a major step forward. Second, in harmonizing long-term nominal and price series for output and intermediate inputs STAN and EU KLEMS employ different vintages of National Accounts as well as different sector classifications.

The observed differences in energy consumption series between the two data sources arise also from two methodological issues. First, for the most part IEA energy consumption data are based on 'mini questionnaires' received from national administrations of OECD countries as well as on monthly oil questionnaires, whereas within the EU KLEMS framework energy is defined as an intermediate input that is derived from national accounts and supply-and-use tables. Second, the EU KLEMS intermediate energy input series include energy used for transformation and own use, whereas this is excluded from IEA final energy consumption data. For most sectors, only a (very) small part of intermediate energy input reflects energy used for transformation and own use. However, the picture might be different in those sectors that make use of large-scale cogeneration of heat and power (CHP) and/or are characterized by a relatively large amount of non-energy use, i.e. fuels that are used as raw materials (feedstock). The issue of non-energy (feedstock) use plays an important role in the Chemical sector, with the Petrochemical industry consuming large quantities of fuel as feedstock.

We now move beneath the aggregate level by presenting in Tables 2 and 3 the annualized energy intensity growth rates in, respectively, 25 Manufacturing subsectors and 23 Services subsectors for selected (clusters of) countries.

\footnotetext{
${ }^{6}$ The energy intensity growth differential is especially large in the U.S. Manufacturing sector for the period 19952005: $-6.4 \%$ (EU KLEMS) versus $-0.7 \%$ (IEA/STAN). We note that the EU KLEMS data for the USA correspond relatively well with the findings of Huntington (2010) who uses a recently developed dataset, combining energy data from the U.S. Energy Information Administration and economic data from the U.S. Bureau of Economic Analysis, to analyze energy intensity changes in the USA. Measured over the period 1997-2006 he finds that aggregate Manufacturing energy intensity decreased on average with $5.8 \%$ per year. Using EU KLEMS data we find $-6.2 \%$, whereas using IEA/STAN data we find a remarkable $-1.0 \%$ (for the period 1997-2005, since we do not have data for 2006).

${ }^{7}$ Supplementary data presented in Appendix A do not reveal a clear cross-country pattern regarding the differences between the two data sources. Also, these data show that the IEA database provides a more extensive coverage than EU KLEMS in terms of energy use data, while the opposite is true regarding value added data where coverage by EU KLEMS is more extensive than by STAN. In terms of internationally comparable energy intensity series, EU KLEMS provides a more extensive coverage than the IEA-STAN combination. For details see Appendix A, Tables A.4 and A.5.
} 


\section{MANUFACTURING}

FOOD, BEVERAGES AND TOBACCO

Food and beverages

Tobacco

TEXTILES, LEATHER AND FOOTWEAR

Textiles

Leather and footwear

WOOD AND CORK

PULP, PAPER , PRINTING AND PUBLISHING

Pulp and paper

Printing, publishing and reproduction

\section{CHEMICALS}

NON-METALLIC MINERALS

BASIC METALS

MACHINERY

Fabricated metal

Machinery nec

Office, accounting and computing machinery

Electrical engineering

TRANSPORT EQUIPMENT

Motor vehicles, trailers and semi-trailers

Other transport equipment

NON-SPECIFIED INDUSTRY

Rubber and plastics

Medical, precision and optical instruments

Manufacturing nec; recycling

\begin{tabular}{|c|c|c|c|c|c|c|c|}
\hline NACE & Us & & JAP & & OECD-18 & EU-10 & EU-4 \\
\hline rev1 code & $\begin{array}{r}1980 \\
-2005\end{array}$ & $\begin{array}{r}1995 \\
-2005\end{array}$ & $\begin{array}{r}1980 \\
-2005\end{array}$ & $\begin{array}{r}1995 \\
-2005\end{array}$ & $\begin{array}{r}1995 \\
-2005\end{array}$ & $\begin{array}{r}1995 \\
-2005\end{array}$ & $\begin{array}{r}1995 \\
-2005\end{array}$ \\
\hline $15 \mathrm{t} 22,24 \mathrm{t} 37$ & -3.7 & -6.4 & -2.5 & -2.5 & -3.7 & -1.5 & -5.1 \\
\hline $15 \mathrm{t} 16$ & -2.4 & -2.3 & 2.9 & 1.3 & -0.7 & 0.1 & -2.7 \\
\hline 15 & -3.1 & -3.3 & 2.7 & 0.9 & -1.4 & -0.1 & -2.9 \\
\hline 16 & 5.3 & 8.5 & 0.7 & 1.1 & 3.6 & 0.4 & 0.9 \\
\hline $17 \mathrm{t} 19$ & -3.3 & -5.2 & 3.9 & 4.8 & -0.9 & -0.3 & -3.0 \\
\hline $17 \mathrm{t} 18$ & -3.6 & -5.4 & 3.9 & 5.0 & -1.0 & -0.6 & -2.3 \\
\hline 19 & -0.3 & -2.4 & 6.0 & 2.6 & -0.1 & 0.9 & -8.1 \\
\hline 20 & -2.5 & -1.6 & -- & -- & -0.5 & 1.4 & -0.1 \\
\hline $21 \mathrm{t} 22$ & -2.5 & -5.2 & 0.7 & 0.0 & -3.2 & -1.2 & 0.3 \\
\hline 21 & -3.3 & -7.4 & -0.1 & -1.2 & -4.8 & -2.1 & -0.2 \\
\hline 22 & -1.2 & -2.1 & 2.4 & 2.0 & -1.0 & -1.0 & -0.5 \\
\hline 24 & -2.9 & -5.4 & -5.3 & 0.3 & -3.8 & -3.1 & 5.2 \\
\hline 26 & -2.8 & -2.6 & -2.3 & -1.4 & -1.7 & 0.1 & -11.4 \\
\hline 27 & -3.3 & -4.8 & -1.5 & -0.3 & -1.4 & -0.1 & 0.2 \\
\hline $28 \mathrm{t} 32$ & -4.8 & -8.6 & -2.7 & -4.6 & -5.2 & -2.7 & -9.8 \\
\hline 28 & -1.9 & -2.7 & 0.1 & 0.9 & -1.3 & -1.2 & -8.4 \\
\hline 29 & -1.6 & -3.0 & -0.4 & -1.7 & -2.2 & -3.0 & -8.2 \\
\hline 30 & -10.4 & -15.5 & -7.2 & -5.4 & -11.2 & -11.1 & -17.6 \\
\hline $31 t 32$ & -10.1 & -14.8 & -7.9 & -8.9 & -9.5 & -3.8 & -10.1 \\
\hline $34 \mathrm{t} 35$ & -2.2 & -4.8 & -0.9 & -1.5 & -2.7 & -1.6 & -10.5 \\
\hline 34 & -3.5 & -8.1 & -1.4 & -1.7 & -3.5 & -1.2 & -14.4 \\
\hline 35 & -0.9 & -1.2 & 2.3 & 0.0 & -1.2 & -3.6 & -1.1 \\
\hline $25,33,36 \mathrm{t} 37$ & -2.5 & -3.0 & 1.2 & 0.7 & -1.4 & -0.9 & -6.7 \\
\hline 25 & -4.1 & -4.2 & 0.6 & -0.7 & -1.8 & -1.2 & -6.2 \\
\hline 33 & -2.3 & -1.9 & 1.1 & 2.8 & -2.1 & -4.0 & -0.5 \\
\hline $36 \mathrm{t} 37$ & -2.4 & -2.7 & 1.6 & 0.3 & -1.1 & 1.1 & -7.6 \\
\hline
\end{tabular}




\begin{tabular}{|c|c|c|c|c|c|c|c|c|}
\hline & \multirow{2}{*}{$\begin{array}{l}\text { NACE } \\
\text { rev1 code }\end{array}$} & \multicolumn{2}{|c|}{ USA } & \multicolumn{2}{|c|}{ JAPAN } & \multirow{2}{*}{$\begin{array}{r}\text { OECD-18 } \\
1995 \\
-2005\end{array}$} & \multirow{2}{*}{$\begin{array}{r}\text { EU-10 } \\
1995 \\
-2005\end{array}$} & \multirow{2}{*}{$\begin{array}{r}\text { EU-4 } \\
1995 \\
-2005\end{array}$} \\
\hline & & $\begin{array}{r}1980 \\
-2005\end{array}$ & $\begin{array}{r}1995 \\
-2005\end{array}$ & $\begin{array}{r}1980 \\
-2005\end{array}$ & $\begin{array}{r}1995 \\
-2005\end{array}$ & & & \\
\hline SERVICES & $\begin{array}{c}\mathrm{GtH}, \mathrm{J}, \mathrm{LtO}, \\
64,71 \mathrm{t} 74\end{array}$ & -1.8 & -1.3 & 1.8 & 0.8 & -1.5 & -0.6 & -2.4 \\
\hline WHOLESALE AND RETAIL TRADE & G & -3.8 & -2.9 & 0.0 & -0.8 & -1.8 & -0.8 & -5.3 \\
\hline Sale, maintenance, repair motor vehicles and -cycles; retail sale of fuel & 50 & -4.6 & -5.1 & 5.0 & -0.2 & -2.1 & 0.5 & 1.0 \\
\hline Other Retail trade; repair of household goods & 52 & -3.2 & -4.2 & 1.8 & -0.5 & -2.1 & 0.8 & -4.6 \\
\hline HOTELS AND RESTAURANTS & $\mathrm{H}$ & -0.3 & -1.1 & 3.5 & 4.1 & 0.4 & 0.1 & -2.1 \\
\hline POST AND TELECOMMUNICATIONS & 64 & -2.6 & -3.3 & 1.5 & 4.2 & -1.1 & -2.7 & -9.7 \\
\hline FINANCIAL INTERMEDIATION & $\mathrm{J}$ & -1.3 & -1.7 & -1.3 & 0.0 & -1.5 & -0.5 & 0.4 \\
\hline Financial intermediation, except insurance and pension funding & 65 & -2.6 & -2.8 & -1.5 & -0.9 & -1.9 & -2.4 & -3.5 \\
\hline Insurance and pension funding, except compulsory social security & 66 & 1.0 & 1.0 & -0.6 & 2.3 & 3.1 & 5.7 & 10.1 \\
\hline Activities related to financial intermediation & 67 & -- & -- & -- & -- & 0.4 & 0.2 & -11.7 \\
\hline Renting of machinery and equipment & 71 & 2.7 & 3.6 & -13.1 & -18.8 & 0.0 & -0.3 & -1.5 \\
\hline Computer and related activities & 72 & -3.2 & -1.4 & 3.1 & -1.1 & -2.4 & -3.1 & -2.8 \\
\hline Research and development & 73 & -1.9 & 2.0 & 2.5 & 3.9 & 1.7 & -0.1 & 0.5 \\
\hline Other business activities & 74 & -1.8 & 0.2 & 2.2 & 0.9 & -0.1 & -0.6 & -7.8 \\
\hline PUBLIC ADMIN, DEFENCE; COMPULSORY SOCIAL SECURITY & $\mathrm{L}$ & 0.8 & 0.9 & 3.0 & -0.6 & -2.3 & 1.3 & -0.3 \\
\hline EDUCATION & M & -0.9 & 1.0 & 3.8 & 3.4 & -1.3 & 1.5 & 2.5 \\
\hline HEALTH AND SOCIAL WORK & $\mathrm{N}$ & -0.3 & -1.0 & 2.4 & 0.6 & -1.8 & -2.2 & 0.5 \\
\hline OTHER COMMUNITY, SOCIAL AND PERSONAL SERVICES & $\mathrm{O}$ & -2.5 & -0.9 & 3.4 & 1.6 & -0.2 & 0.0 & 2.3 \\
\hline Sewage and refuse disposal, sanitation and similar activities & 90 & 1.0 & 0.8 & 9.0 & 2.1 & 1.4 & 2.4 & 3.3 \\
\hline Activities of membership organizations nec & 91 & -2.8 & -0.3 & -0.3 & -0.5 & 0.0 & 0.5 & -1.4 \\
\hline Recreational, cultural and sporting activities & 92 & -2.1 & -1.1 & 4.1 & 1.2 & -0.1 & -0.6 & -0.1 \\
\hline Other service activities & 93 & -3.2 & -1.7 & 1.6 & 2.1 & 0.4 & -0.9 & 2.4 \\
\hline
\end{tabular}


Table 2 shows that in the USA and the European Union virtually all manufacturing subsectors exhibit negative growth rates of energy intensity; main exceptions are the sectors Tobacco (especially in the USA) and Chemicals in the EU-4 region (Eastern Europe). In Japan, however, the picture is much more diverse, with energy intensity increasing in a range of sectors, most notably in the sectors Food, Textile, Printing, and Medical Instruments. In all countries and regions, the largest decreases in energy intensity have been realized in the sectors Office/Accounting/Computing Machinery and Electrical Engineering as well as in the energy intensive sector Non-Metallic Minerals. In contrast, Table 3 shows that across countries and regions energy intensity levels tend to increase in a fairly wide range of Services subsectors. This is especially true in Japan.

\section{Structural Change}

Changes in energy intensity at the aggregate level result not only from energy efficiency improvements in individual sectors (an 'efficiency effect'), but also from changes in the sector composition of the economy (a 'structure effect'). The latter is caused by the fact that sectors differ inherently in terms of their requirement of energy inputs relative to other inputs like capital and (skilled) labor. In this section we present the results of an index number decomposition (or shift-share) analysis that we can use to decompose changes in aggregate energy intensity into a so-called structure effect and an efficiency effect. To describe the essence of index number decomposition methodology algebraically, let $i$ denote the sectors of the economy and let $Y$ and $E$ represent output (value added) and energy consumption, respectively. Aggregate energy intensity $I$, defined as the ratio of energy to output, can then be written as:

$$
I=\frac{E}{Y}=\sum_{i} \frac{E_{i}}{Y_{i}} \frac{Y_{i}}{Y}=\sum_{i} I_{i} S_{i}
$$

In this equation, $I_{i}$ represents the within-sector energy intensity and $S_{i}$ is the share of the sector in total value added. The efficiency effect is then calculated as the weighted sum of energy intensity changes of individual sectors $\left(\Delta I_{i}\right)$ while keeping the sector composition of the economy constant. Conversely, the structure effect is calculated as the weighted sum of changes in the value added share of individual sectors $\left(\Delta S_{i}\right)$ while keeping the within-sector energy intensity constant. Decomposition analyses in the field of energy studies have used a variety of weights, which translates into a range of applied decomposition approaches (see Ang et al. 2003, Ang 2004, Ang et al. 2004, Boyd and Roop 2004, and Zhang and Ang 2001, for reviews and details). In this study we use the so-called log mean Divisia index method (LMDI I) as introduced by Ang and Liu (2001). In its additive form this method derives, respectively, the efficiency effect $(E F F)$ and structure effect (STR) between period 0 and $t$ according to:

$$
E F F=\sum_{i} w_{i} \Delta I_{i}
$$


and

$$
S T R=\sum_{i} w_{i} \Delta S_{i}
$$

where $w_{i}$ is the weighting function defined as $w_{i}=L\left(V_{i, t}, V_{i, 0}\right)$, with $V_{i}=\Sigma I_{i} S_{i}$ and $L$ the logarithmic average of two positive numbers $a$ and $b$ given by $L(a, b)=(a-b) / \ln (a / b)$. The choice for this approach is primarily motivated by its ability to satisfy the factor-reversal test, i.e. it provides perfect decomposition results without a residual. Moreover, this approach can handle zero values effectively, the results are invariant to scaling and it satisfies the time-reversal test, i.e. estimated values between period 0 and $t$ and period $t$ and 0 are equal (in absolute terms). In the two-factor case, this approach is equivalent to the Fisher ideal index method that is defined as the square root of the product (i.e. the geometric average) of the Laspeyres and Paasche indices (Ang 2004, Boyd and Roop 2004). For the aforementioned reasons the LMDI and Fisher ideal index methods have emerged as the preferred methods in energy decomposition analysis (Ang 2004). ${ }^{8}$

In Table 4 we provide the results of our aggregate decomposition analysis based on 21 -sectors. ${ }^{9}$ For each country we present for different time periods the average annualized energy intensity growth rates before decomposition ('Gross') and after decomposition ('Net'), i.e. after correcting for activity shifts across sectors in the economy (the structure effect). ${ }^{10}$ At the right-hand side of Table 4 we list per country the percentage contribution of the structure effect to the decrease in gross annualized growth rates of energy intensity - a positive number indicates that changes in the sector composition of the economy led to increasing aggregate energy intensity.

\footnotetext{
8 The generalized Fisher approach has its roots in studies by Siegel (1945) and Shapley (1953); see De Boer (2009). Also, note that a simple relationship exists between the additive and multiplicative form, which thus can be easily related to each other.

9 A consistent comparison across countries prevents us from using a more detailed sector decomposition approach, given cross-country differences in data availability at the lowest level of sector detail.

${ }^{10}$ Since the EU KLEMS database provides volume indices of aggregate intermediate energy inputs only (including all energy mining products, oil refining products and electricity and gas products), we are not able to correct our efficiency effect for changes in the fuel input mix. The latter might have an impact because energy carriers (natural gas, electricity, coal, etc.) differ in terms of available energy, i.e. they differ in terms of quality or efficiency in delivering energy services (Berndt 1978, Cleveland et al. 2000).
} 
Table 4. Decomposition of total average annual growth rate of energy intensity (TOT) into an efficiency effect (EFF) and a structure effect (STR)

\begin{tabular}{|c|c|c|c|c|c|c|c|c|c|c|c|c|}
\hline & \multicolumn{9}{|c|}{ Average annual growth rate energy intensity } & \multicolumn{3}{|c|}{$\%$ contribution Structure Effect } \\
\hline & \multicolumn{3}{|c|}{$1970-2005$} & \multicolumn{3}{|c|}{ 1980-2005 } & \multicolumn{3}{|c|}{$1995-2005$} & 1970 & 1980 & 1995 \\
\hline & EFF & STR & TOT & EFF & STR & TOT & EFF & STR & TOT & STR & STR & STR \\
\hline Denmark & -2.0 & -0.7 & -2.7 & -2.3 & -0.8 & -3.1 & -1.9 & -1.2 & -3.2 & -27 & -26 & -40 \\
\hline Finland & 0.5 & 0.1 & 0.6 & -1.1 & 0.1 & -1.0 & -2.6 & -1.5 & -4.1 & 15 & 7 & -37 \\
\hline South Korea & 0.0 & 1.2 & 1.2 & -0.1 & 0.2 & 0.2 & 2.6 & -0.4 & 2.2 & 98 & 154 & -17 \\
\hline United Kingdom & 0.9 & -1.3 & -0.4 & -0.4 & -1.2 & -1.6 & -0.3 & -2.1 & -2.4 & -368 & -76 & -87 \\
\hline USA & -2.0 & -0.5 & -2.5 & -2.7 & -0.5 & -3.2 & -3.4 & -0.7 & -4.1 & -21 & -16 & -16 \\
\hline Austria & & & & 0.2 & 0.2 & 0.4 & -0.2 & 0.4 & 0.3 & & 45 & 166 \\
\hline Belgium & & & & -0.4 & 0.5 & 0.1 & -1.1 & -0.5 & -1.6 & & 457 & -31 \\
\hline France & & & & -3.1 & 1.0 & -2.1 & -1.5 & -0.5 & -2.0 & & 48 & -24 \\
\hline Germany & & & & -2.4 & -0.5 & -2.9 & -2.1 & -0.2 & -2.4 & & -17 & -9 \\
\hline Japan & & & & -0.1 & -0.9 & -1.0 & 0.3 & -1.3 & -1.0 & & -95 & -126 \\
\hline Netherlands & & & & -0.3 & 0.0 & -0.3 & -1.3 & -0.3 & -1.7 & & 12 & -20 \\
\hline Spain & & & & -0.6 & -0.5 & -1.1 & 3.8 & -1.1 & 2.7 & & -49 & -39 \\
\hline Czech Republic & & & & & & & -1.4 & 0.4 & -1.1 & & & 36 \\
\hline Hungary & & & & & & & -5.5 & -1.1 & -6.6 & & & -17 \\
\hline Italy & & & & & & & -4.8 & -0.7 & -5.5 & & & -12 \\
\hline Poland & & & & & & & -1.3 & 0.5 & -0.9 & & & 53 \\
\hline Slovakia & & & & & & & -7.2 & 1.3 & -5.8 & & & 23 \\
\hline Sweden & & & & & & & -1.4 & -2.6 & -4.0 & & & -64 \\
\hline EU-10 & & & & -1.3 & & -1.7 & -1.0 & -0.7 & -1.7 & & -22 & -42 \\
\hline EU-4 & & & & & & & -3.0 & 0.3 & -2.6 & & & 12 \\
\hline OECD-18 & & & & & & & -1.9 & -0.6 & -2.6 & & & -25 \\
\hline
\end{tabular}


From Table 4 it can be seen that in general changes in energy intensity at the aggregate economy level have been influenced more by (technology-driven) efficiency improvements within sectors than by structural changes. This finding corresponds with the findings of most energy decomposition studies (cf. Liu and Ang 2007). Nevertheless, in various countries structural change has a large influence on aggregate energy intensity changes: during the period 1995-2005 structural changes explain, respectively, $25 \%$ and $42 \%$ of the aggregate decrease in energy intensity across the sample of 18 OECD countries and the EU-10 countries (Western Europe). In the United Kingdom and Japan structural changes are by far the principal sources of reductions in aggregate energy intensity; in Japan after 1995 they even offset decreasing within-sector energy efficiency. Moreover, Table 4 shows that in the cluster of EU-10 countries (Western Europe) the role of structural change in driving down aggregate energy intensity has been increasing over time (22\% measured over 1980-2005, 42\% measured over 1995-2005). In contrast, except for Hungary, in the Eastern European countries (EU-4) structural changes have contributed to increasing aggregate energy intensity.

It is beyond the scope of this paper to discuss all country-specific results in detail. Also, comparison of our results with findings of existing studies is not straightforward because of cross-study differences in time periods, sector definitions, levels of aggregation and decomposition methodology. Nevertheless, we note that for various countries our results confirm findings of related studies. For example, the increase in aggregate energy intensity in Spain during the period 1995-2005 has also been reported by Mendiluce et al. (2010). For the USA, Huntington (2010) finds for the period 1972-2006 an average annual energy intensity growth rate of $-2.3 \%$ at the aggregate economy level. EU KLEMS data give $-2.7 \%$ for the period $1972-2005$ and $-2.5 \%$ for the period 1970-2005 (we have no data for 2006). As regards the role of structural change, Huntington (2010) finds that during the period 1972-2006 structural changes explain about $18 \%$ of aggregate energy intensity decrease in the USA (excluding residential and personal transportation sectors, like in our case). Metcalfe (2008) reports $14 \%$, measured of the period 1970-2003. In comparison, we find fairly similar results: $21 \%$ for the period $1970-2005$, and $16 \%$ for periods 1980-2005 and 1995-2005.

Further comparison of our results with these and other previous studies suggest that sector definitions, rather than the level of aggregation or decomposition methodology, play a crucial role in explaining different results from decomposition analyses across studies. For example, using a 65 -sector decomposition approach based upon the North American Industry Classification System (NAICS), Huntington (2010) finds for the USA that between 1997 and 2006 structural changes explain, respectively, 39\% and 92\% of energy intensity reductions in the Manufacturing and Services sector. In contrast, we find these percentages to be, respectively, 23\% and 10\% (during the period 1995-2005) using the same decomposition methodology and a very similar degree of subsector detail, but based upon 
the Standard Industrial Classification System (SIC). In comparison, using a similar two-digit decomposition approach based upon SIC, Metcalfe (2008) and Lescaroux (2008) find that structural changes contributed about $18 \%$ to U.S. Manufacturing energy intensity changes during the period 1974-1997/98. ${ }^{11}$ This is well in line with our results: measured over the period 1980-2005 and 1995-2005 we find this percentage contribution to be, respectively, $18 \%$ and $22 \%$.

Further examination of the contribution of individual sectors to the aggregate results presented above reveals that, except for the EU-4 region, the shift from Manufacturing to Services is the principal source of the observed contribution of the structure effect to aggregate energy intensity decline. The aggregate energy efficiency effect is mainly driven by declining energy intensity in the energy-intensive sectors Chemicals, Non-Metallic Minerals, Basic Metals and (especially in the USA) Pulp, Paper and Printing. Energy intensity decline in the Services sector is mainly driven by energy efficiency improvements within the Wholesale and Retail Trade sector, at quite some distance followed by the sector Renting, Computer, R\&D and Other Business (especially in the EU-10 region). The increasing energy intensity levels in the Japanese Services sector are largely caused by a structural shift to the sector Health and Social Work, in combination with decreasing energy efficiency in a range of subsectors, most notably Hotels and Restaurants. ${ }^{12}$

\section{Convergence}

In this section we analyze the evolution of the observed cross-countries differences in energy intensity developments. These differences may change over time as the result of factor accumulation, factor price changes and technological change, which in turn can be facilitated by processes such as trade, foreign direct investment (FDI), learning and market conditions (Miketa and Mulder 2005, Mulder and De Groot 2007). On the one hand, these processes may contribute to cross-country convergence of energy intensity levels by means of technology transfer and knowledge spillovers to relatively backward countries, factor price equalization or diminishing returns to capital accumulation. On the other hand, these processes may cause diverging energy intensity trends because learning effects, externalities and market imperfections allow for economy-wide increasing returns to capital accumulation and international specialization, which in turn may result in multiple steady states and different path of factor accumulation (Grossman and Helpman 1991). Moreover, there is some reason to believe that technology diffusion and knowledge spillovers are local rather than global (see, for example, Keller 2002) which raises the possibility that cross-country convergence of energy intensity levels depend on the spatial dimension of technological progression (Mulder et al. 2011).

\footnotetext{
${ }^{11}$ Lescaroux (2008) finds that $7 \%$ of a total $41.9 \%$ decline is to be explained from structural change.

${ }^{12}$ See Table A.6 in Appendix A for more details.
} 
Against this background, we document and decompose patterns of cross-country convergence of energy intensity levels. Convergence can be understood both in terms of levels and growth rates, which translates into a distinction between so-called $\sigma$-convergence and $\beta$-convergence (e.g., Barro 1991, Barro and Sala-i-Martin 1992). The former refers to a decreasing variance of cross-country differences in productivity or intensity levels, while the latter refers to a tendency of countries with relatively high (low) initial intensity (productivity) levels to grow relatively fast, building upon the proposition that growth rates tend to decline as countries approach their steady state..$^{13}$ Below we provide cross-sector evidence for both types of convergence. We conclude by extending the $\beta$-decomposition approach developed by Wong (2006) to quantify the role of structural change and sectoral efficiency growth in driving aggregate patterns of energy intensity convergence across OECD countries.

Figure 1 presents for different samples of countries the $\sigma$-convergence results for our main sectors, measured as the unweighted cross-country standard deviation of the log of energy intensity over time. Figure 1 shows at the aggregate economy diverging energy intensity levels until the end of the 1990s, but thereafter energy intensity levels clearly tend to converge across OECD countries. From the Figure it can be seen that this result is mainly driven by a remarkable strong and robust trend-break in the Manufacturing sector, where a pattern of slow divergence after 1995 turns into a pattern of rapid convergence. In addition, across EU-10 countries (Western Europe) energy intensity levels in the Services sector also converged rapidly.

\footnotetext{
${ }^{13}$ Obviously, $\sigma$-convergence and $\beta$-convergence are closely related. A narrowing dispersion of cross-country productivity differences implies that countries with a relatively poor initial productivity performance tend to grow relatively fast. However, as has been argued by Quah (1993), a statistically significant inverse relationship between the initial level and the growth rate of productivity performance can be consistent with constant or even increasing cross-country productivity differences - a phenomenon known as Galton's Fallacy of regression towards the mean. In other words, $\beta$-convergence is a necessary but not a sufficient condition for $\sigma$-convergence.
} 
Figure 1. Results of $\sigma$-convergence analysis, measured as standard deviation of log(energy intensity)
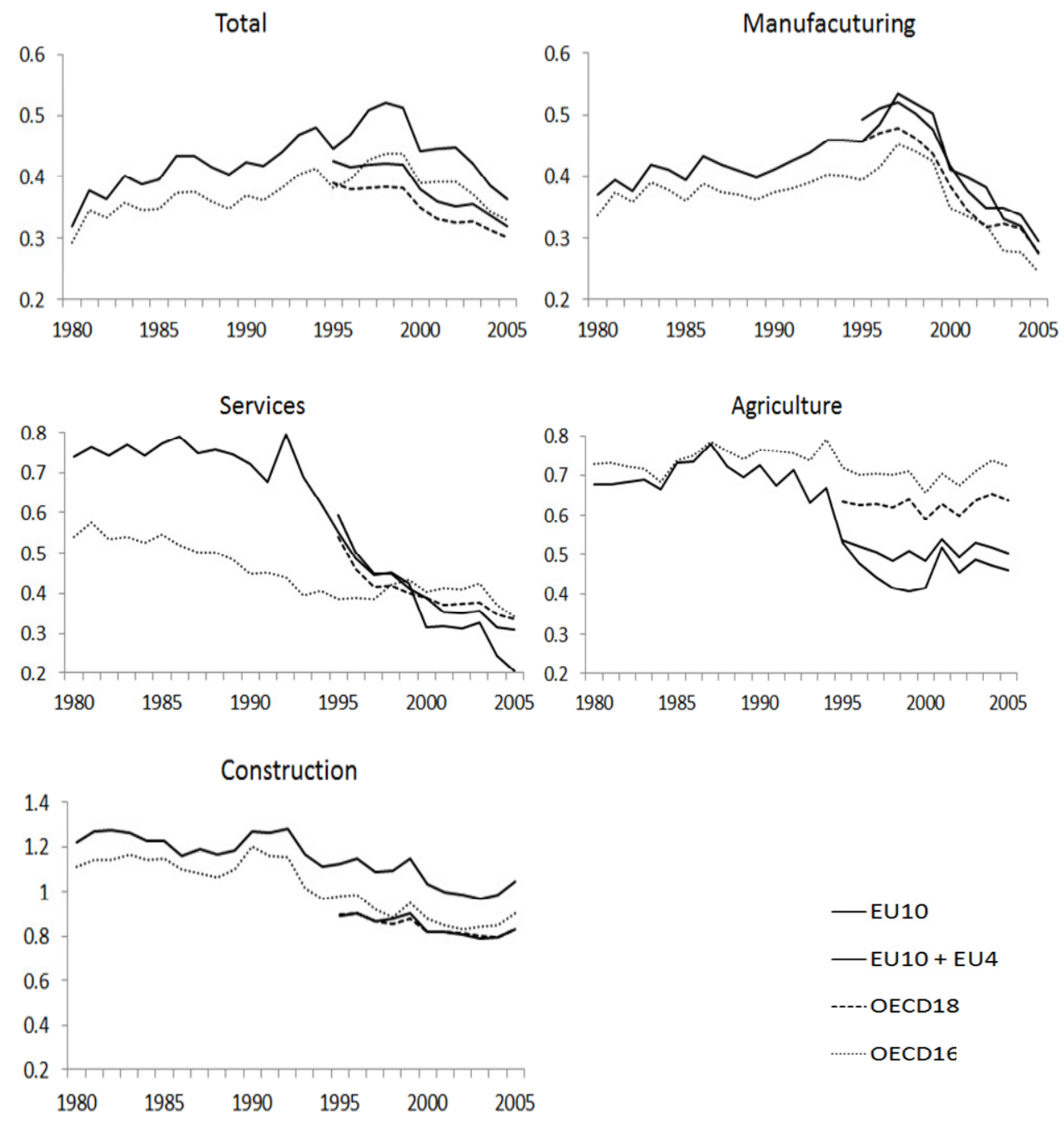

In Table 5 we present the results of a more detailed sector analysis of $\sigma$-convergence patterns. From the table it can be seen that the aforementioned trend-break in Manufacturing is largely caused by strong cross-country convergence of energy intensity levels in the Food industry. Furthermore, the table shows that within the Manufacturing sector convergence is especially strong in the sectors Textiles and Leather, Wood and Cork, Basic Metals and, before 1995, also Non-Metallic Minerals. In contrast, in the Machinery industry differences in energy intensity levels across countries increased considerably, especially within the EU-10 region. Albeit much weaker, during the period 1995-2005 we also find evidence of $\sigma$-divergence in the Chemical and Non-Specified Industries, especially when measured at the OECD-18 level. As a result of these and other trends, in 2005 cross-country variation in energy intensity levels is relatively high in the subsectors Wood and Non-Specified Industry and relatively low in the 
subsectors Food and Textiles. Except for the Paper \& Pulp industry, cross-country differences in the energy-intensive subsectors are relatively low.

Table 5. Standard deviation of log energy intensity per sector

\begin{tabular}{|c|c|c|c|c|c|}
\hline & \multicolumn{3}{|c|}{$\%$ Change in standard deviation } & \multirow{2}{*}{\multicolumn{2}{|c|}{$\begin{array}{c}\text { Standard deviation } \\
2005\end{array}$}} \\
\hline & \multirow{2}{*}{$\begin{array}{c}1980 \\
-2005 \\
\text { EU-10 }\end{array}$} & \multicolumn{2}{|c|}{ 1995-2005 } & & \\
\hline & & EU-10 & OECD-18 & EU-10 & OECD-18 \\
\hline AGRICULTURE & -32.1 & -13.0 & 0.7 & 0.46 & 0.64 \\
\hline CONSTRUCTION & -14.4 & -7.2 & -7.0 & 1.04 & 0.83 \\
\hline MANUFACTURING & -25.6 & -39.6 & -39.5 & 0.27 & 0.28 \\
\hline Food, Beverages and Tobacco & -3.8 & -28.3 & -28.1 & 0.24 & 0.26 \\
\hline Textiles, Leather and Footwear & -64.9 & -37.0 & -13.1 & 0.17 & 0.48 \\
\hline Wood and Cork & -33.6 & 6.5 & -1.9 & 1.20 & 0.92 \\
\hline Pulp, Paper and Printing & -17.3 & -17.6 & -13.8 & 0.77 & 0.74 \\
\hline Chemicals & -3.1 & 7.5 & 24.1 & 0.51 & 0.58 \\
\hline Non-Metallic Minerals & -43.2 & -7.5 & -1.7 & 0.29 & 0.37 \\
\hline Basic Metals & -74.1 & -55.8 & -37.7 & 0.28 & 0.44 \\
\hline Machinery & 41.9 & 109.7 & 30.0 & 0.59 & 0.74 \\
\hline Transport Equipment & -9.7 & -10.4 & -39.5 & 0.48 & 0.49 \\
\hline Non-Specified Industry & -1.7 & 6.8 & 14.6 & 0.91 & 0.90 \\
\hline SERVICES & -56.4 & -47.4 & -42.5 & 0.27 & 0.45 \\
\hline Wholesale and Retail Trade & 14.3 & 10.5 & 4.0 & 0.54 & 0.82 \\
\hline Hotels and Restaurants & -16.6 & 31.5 & -2.9 & 0.62 & 0.82 \\
\hline Post and Telecommunications & -36.4 & -0.6 & -5.2 & 0.69 & 0.54 \\
\hline Financial Intermediation & -57.5 & -26.8 & -38.1 & 0.35 & 0.41 \\
\hline Renting, Computer, R\&D and Other Business & -88.8 & -82.3 & -55.2 & 0.16 & 0.33 \\
\hline Public Administration and Defense & -65.5 & -45.8 & -38.6 & 0.48 & 0.53 \\
\hline Education & -66.1 & -48.6 & -2.6 & 0.44 & 0.64 \\
\hline Health and Social Work & 15.0 & -10.5 & -13.9 & 0.52 & 0.51 \\
\hline Other Community, Social and Personal Services & -72.4 & -62.9 & -37.8 & 0.20 & 0.34 \\
\hline TOTAL & 13.9 & -18.6 & -22.6 & 0.34 & 0.30 \\
\hline
\end{tabular}

As regards the Services sector, Table 5 shows that the relatively rapid convergence of energy intensity levels across EU-10 countries (Western Europe) is mainly driven by considerable decreasing crosscountry variation in energy intensity levels within the sectors Renting, Other Services, Public Administration and Defense and Education. In contrast, we find evidence of increasing cross-country differences in energy intensity levels within the sector Wholesale and Retail Trade and, for the EU-10 region, also in the sector Hotels and Restaurants. As a result of these and other trends, in 2005 cross- 
country variation in energy intensity levels is relatively high in the subsectors Hotels \& Restaurants and Post \& Telecommunication, and relatively low in the subsectors Other Business and Other Services.

Next, we present the results of our $\beta$-convergence analysis, testing for the assumption that countries with relatively high initial energy intensity levels tend to catch up to more advanced countries. We do so by regressing for each sector $i$ the growth rate of energy productivity (i.e. the ratio of economic output to energy input; it is thus the inverse of energy intensity $I$, and we denote energy productivity by $\left.I^{*}\right)$ between period 0 and $t$, on its initial level, generating an estimate of $\beta$, according to:

$$
\Delta I_{j t}^{*}=\alpha+\beta \ln \left(I_{j 0}^{*}\right)+\varepsilon_{j t}
$$

with $j$ denoting the cross-country dimension and $\varepsilon_{j t}$ the standard error. A statistically significant negative estimate of $\beta$ is taken as evidence of convergence, because it suggests that countries with relatively low initial energy productivity levels catch-up to more advanced economies. This so-called unconditional convergence specification implicitly assumes that across countries energy intensity levels converge towards a uniform steady state. This, of course, is a strong assumption because economies differ in terms factors that may impact energy intensity levels - including, for example, energy prices, energy mix, technology levels, policy stringency, scale economies, etc.. Hence, instead it is more realistic to assume that energy intensity levels converge to multiple steady-states, which are conditional on country-specific characteristics. To this aim, we extend our analysis by including fixed effects in our panel data framework, according to:

$$
\Delta I_{j t}^{*}=\beta \ln \left(I_{j 0}^{*}\right)+\mu_{j}+\varepsilon_{j t}
$$

with $\mu_{j}$ representing unspecified country-specific (fixed) effects. These fixed effects are unobservable individual 'country-effects' capturing country-specific tangible and intangible factors that may impact energy intensity levels. Following Islam (1995) we use five-year time intervals in order to reduce the influence of business-cycle fluctuations and serial correlation on the error term. Hence, $\Delta I$ in equation (1) is an average growth rate over a five-year period. Using the estimated values of $\beta$, the speed of convergence $\lambda$ at which the energy-intensity levels are converging to their steady-state level can be derived according to $\lambda=-[(1 / T) \log (\beta+1)]$ with $T$ denoting the length of the time interval under consideration (Barro and Sala-i-Martin, 1992; Islam, 1995). ${ }^{14}$ We present the results of our estimates in Table $7 .^{15}$

\footnotetext{
${ }^{14}$ Since we use five-year time intervals, $T$ equals 5 in our analysis.

15 Because of space limitations, we present the results of our estimates for the period 1970-2005 in Table A.7 in Appendix A. Due to limited data availability these estimates include (only) 5 countries.
} 
TOTAL

AGRICULTURE

CONSTRUCTION

\section{MANUFACTURING}

Food, Beverages and Tobacco

Textiles, Leather and Footwear

Wood and Cork

Pulp, Paper and Printing

Chemicals

Non-Metallic Minerals

Basic Metals

Machinery

Transport Equipment

Non-Specified Industry SERVICES

Wholesale and Retail Trade

Hotels and Restaurants

Post and Telecommunications

Financial Intermediation

Renting, Computer, R\&D, Other Business

Public Administration and Defense

Education

Health and Social Work

Other Comm., Social \& Personal Services

$$
1980-2005
$$

\begin{tabular}{rccc}
\hline & & & \\
\hline$\beta$ & $t$-stat & $R^{2}$ & $\lambda *$ \\
\hline-0.09 & -1.47 & 0.04 & 1.8
\end{tabular}

Fixed Effects

\begin{tabular}{rccc}
\multicolumn{4}{c}{ Fixed Effects } \\
\hline$\beta$ & $t$-stat & $R^{2}$ & $\lambda *$ \\
\hline-0.39 & -3.61 & 0.33 & 9.9
\end{tabular}

$\begin{array}{llll}-0.09 & -1.83 & 0.05 & 1.8\end{array}$

$\begin{array}{llll}-0.07 & -2.02 & 0.07 & 1.4\end{array}$

$-0.12-2.22$

$-0.21 \quad-3.42$

$-0.16 \quad-2.86$

$-0.12 \quad-2.46$

$-0.05 \quad-1.57$

$-0.21 \quad-4.08$

$-0.19-3.31$

$-0.27 \quad-5.42$

$-0.13 \quad-1.63$

$-0.30 \quad-4.17$

$-0.04 \quad-0.90$

$-0.15 \quad-2.81$

$-0.18 \quad-4.30$

$-0.09 \quad-2.24$

$-0.14 \quad-2.07$

$-0.17 \quad-2.77$

$-0.20 \quad-2.92$

$-0.23 \quad-5.78$

$-0.20 \quad-3.48$

$-0.13 \quad-2.04$

$-0.11 \quad-1.94$

11

61

\begin{tabular}{rrrr} 
& & & 1995 \\
\hline$\beta$ & \multicolumn{1}{r}{-stat } & $R^{2}$ & $\lambda *$ \\
\hline-0.20 & -3.09 & 0.17 & 4.4 \\
-0.12 & -1.84 & 0.07 & 2.6 \\
-0.12 & -2.92 & 0.15 & 2.6 \\
-0.25 & -4.04 & 0.26 & 5.8 \\
-0.31 & -3.95 & 0.25 & 7.3 \\
-0.24 & -3.22 & 0.18 & 5.4 \\
-0.08 & -1.29 & 0.04 & 1.6 \\
-0.08 & -2.15 & 0.09 & 1.7 \\
-0.09 & -1.05 & 0.02 & 1.8 \\
-0.34 & -3.80 & 0.24 & 8.4 \\
-0.28 & -6.16 & 0.45 & 6.6 \\
-0.08 & -0.90 & 0.02 & 1.7 \\
-0.36 & -6.41 & 0.47 & 9.0 \\
-0.01 & -0.18 & 0.00 & 0.2 \\
-0.33 & -5.84 & 0.42 & 7.9 \\
-0.35 & -6.21 & 0.45 & 8.6 \\
-0.07 & -1.27 & 0.03 & 1.4 \\
-0.14 & -1.93 & 0.07 & 3.1 \\
-0.35 & -3.58 & 0.21 & 8.5 \\
-0.36 & -5.51 & 0.39 & 8.8 \\
-0.38 & -6.82 & 0.50 & 9.4 \\
-0.39 & -6.26 & 0.46 & 10.0 \\
-0.27 & -4.07 & 0.26 & 6.3 \\
-0.15 & -2.61 & 0.13 & 3.1 \\
& & & \\
\hline
\end{tabular}

18

49
995-2005

\begin{tabular}{rccl}
\multicolumn{4}{c}{ Fixed Effects } \\
\hline$\beta$ & \multicolumn{1}{c}{$t$-stat } & \multicolumn{1}{c}{$R^{2}$} & \multicolumn{1}{c}{$\lambda *$} \\
\hline-0.59 & -4.12 & 0.69 & 17.8 \\
-0.75 & -4.60 & 0.65 & 27.8 \\
-0.86 & -7.20 & 0.75 & 39.9 \\
-0.14 & -0.68 & 0.61 & 3.0 \\
-1.14 & -6.05 & 0.67 & \\
-0.74 & -6.04 & 0.80 & 27.0 \\
-1.03 & -6.77 & 0.75 & \\
-0.54 & -4.14 & 0.78 & 15.7 \\
-0.66 & -5.18 & 0.74 & 21.3 \\
-0.70 & -3.98 & 0.70 & 23.7 \\
-0.64 & -4.51 & 0.74 & 20.2 \\
-0.29 & -1.97 & 0.69 & 6.9 \\
-0.65 & -4.96 & 0.78 & 21.0 \\
-0.59 & -4.83 & 0.82 & 17.7 \\
-0.41 & -3.27 & 0.71 & 10.6 \\
-0.92 & -6.19 & 0.72 & 50.8 \\
-0.96 & -6.09 & 0.69 & 63.4 \\
-0.49 & -3.79 & 0.65 & 13.6 \\
-1.19 & -7.19 & 0.70 & \\
-0.75 & -6.58 & 0.79 & 27.8 \\
-0.38 & -2.78 & 0.69 & 9.6 \\
-0.59 & -3.95 & 0.65 & 17.7 \\
-0.30 & -4.12 & 0.88 & 7.1 \\
-0.53 & -3.80 & 0.69 & 15.3
\end{tabular}

18

49

* Speed of convergence in percentage. 
From Table 7 it can be seen that, measured over the period 1980-2005, the speed of unconditional convergence at the aggregate economy level is $1.8 \%$. Interestingly, looking at per-capita income convergence, empirical growth studies often have reported a rate of convergence of about $2 \%$, under a variety of different conditions. However, using meta-analysis, Abreu et al. (2005) have shown that it is misleading to speak of a natural convergence rate, amongst others, because estimates of different growth regressions come from different populations and correcting for unobserved heterogeneity in technology levels leads to higher estimates of the rate of per-capita income convergence. Our results suggest that similar conclusions hold for cross-country convergence of energy intensity levels. Once we correct for unobservable individual 'countryeffects' (fixed effects) we find considerable higher rates of convergence, supporting the assumption that energy intensity convergence is conditional on country-specific characteristics - including the technology level.

Moreover, contrasting the post-1995 period with earlier years shows that in most sectors the rate of convergence has increased considerably, which can be partly explained by the inclusion of EU-4 countries (Eastern Europe) in the sample - as already observed in Section 3 these transition countries show evidence of catching up to more advanced economies. Also, we find that on average the rate of convergence is considerably higher in Services sectors than in Manufacturing sectors. More specifically, we find a remarkable low rate of convergence in the subsectors Machinery and Pulp, Paper and Printing. In contrast, the subsectors Textiles \& Leather, Food, Transport Equipment and Basic Metals show high rates of convergence, especially when we control for (unobserved) country-specific characteristics. Within Services, the rate of convergence is, as expected, relatively low in the subsectors Public Administration \& Defense, Health and Social Work, and Other Services. In contrast, the rate of convergence is particularly high in the subsectors Wholesale \& Retail Trade and Other Business. Remarkably, the sectors Post \& Telecommunication and Hotels \& Restaurants show strong evidence of catching-up in the period after 1995.

We conclude our analysis by calculating to what extent the observed aggregate pattern of energy intensity convergence is to be explained from, respectively, convergence in the underlying sectoral structure and convergence of efficiency improvements within individual sectors. We do so by applying the sectoral $\beta$ decomposition approach developed by Wong (2006) to our data. We slightly modify his approach by choosing a different underlying decomposition methodology: like in the previous section we use the $\log$ mean Divisia index method (LMDI I), i.e. a perfect decomposition method without a residual. ${ }^{16}$ More specifically, the sectoral $\beta$-decomposition approach is based on the identity:

\footnotetext{
${ }^{16}$ Wong (2006) uses a traditional General Parametric Divisia Method. An important disadvantage of this approach is that it gives a residual (interaction) term that is difficult to interpret.
} 


$$
\beta \equiv \sum_{i} \beta_{e f f}+\sum_{i} \beta_{s t r}
$$

where $\beta_{\text {eff }}$ is the coefficient estimate obtained from regressing for each sector $i$ the weighted growth rate of its energy intensity between period 0 and $t$ on the initial level of aggregate (economy-wide) energy intensity according to:

$$
w_{i} \Delta I_{i}=\beta_{e f f} \ln (I)_{j, 0}+\mu_{j}+\varepsilon_{j t} .
$$

Similarly, where $\beta_{s t r}$ is the coefficient estimate obtained from regressing for each sector $i$ the weighted growth rate of its value added share between period 0 and $t$ on the initial level of aggregate (economy-wide) energy intensity according to:

$$
w_{i} \Delta S_{i}=\beta_{s t r} \ln (I)_{j, 0}+\mu_{j}+\varepsilon_{j t} .
$$

In equations (5) and (6) $w_{i}$ is the LMDI I decomposition weighting function as defined in the previous section; again, $j$ denotes the cross-country dimension, $\varepsilon_{j t}$ the standard error and $\mu_{j}$ the unspecified countryspecific (fixed) effects. The results are presented in Table $8 .{ }^{17}$

From Table 8 it can be seen that the observed patterns of aggregate convergence are almost exclusively caused by convergence of within-sector energy intensity levels. Even stronger, except for the post-1995 conditional convergence estimate, structural changes have somewhat undermined aggregate energy intensity convergence. Moreover, the table shows that Manufacturing sectors are the main source of within-sector energy intensity convergence, especially the sectors Basic Metals, Paper and Non-Specified Industry. However, after 1995 the role of the Services sectors is clearly increasing.

\footnotetext{
${ }^{17}$ Because of space limitations, we present the results of our estimates for the period 1970-2005 in Table A.8 in Appendix A. Due to limited data availability these estimates include (only) 5 countries.
} 


\begin{tabular}{|c|c|c|c|c|c|c|c|c|c|c|c|c|c|c|c|c|}
\hline & \multicolumn{8}{|c|}{$1980-2005$} & \multicolumn{8}{|c|}{$1995-2005$} \\
\hline & \multirow[b]{2}{*}{$\%$} & \multirow[b]{2}{*}{$\beta$} & \multirow[b]{2}{*}{$t$-stat } & \multirow[b]{2}{*}{$R^{2}$} & \multicolumn{4}{|c|}{ Fixed Effects } & \multirow[b]{2}{*}{$\%$} & \multirow[b]{2}{*}{$\beta$} & \multirow[b]{2}{*}{$t$-stat } & \multirow[b]{2}{*}{$R^{2}$} & \multicolumn{4}{|c|}{ Fixed Effects } \\
\hline & & & & & $\%$ & $\beta$ & $t$-stat & $R^{2}$ & & & & & $\%$ & $\beta$ & $t$-stat & $R^{2}$ \\
\hline \multicolumn{17}{|l|}{ Efficiency effect per sector } \\
\hline Agriculture & 13 & -0.01 & -1.55 & 0.04 & 8 & -0.03 & -2.12 & 0.23 & 6 & -0.01 & -1.18 & 0.03 & 5 & -0.03 & -0.99 & 0.42 \\
\hline Construction & 2 & 0.00 & -0.25 & 0.00 & 3 & -0.01 & -1.16 & 0.09 & 1 & 0.00 & -0.37 & 0.00 & 6 & -0.04 & -3.05 & 0.55 \\
\hline Food, Beverages and Tobacco & 11 & -0.01 & -2.28 & 0.08 & 8 & -0.03 & -4.06 & 0.32 & 7 & -0.01 & -2.90 & 0.15 & 2 & -0.01 & -0.68 & 0.38 \\
\hline Textiles, Leather and Footwear & 6 & 0.00 & -1.25 & 0.03 & 6 & -0.02 & -2.79 & 0.18 & 4 & -0.01 & -2.88 & 0.15 & 2 & -0.01 & -2.16 & 0.69 \\
\hline Wood and Cork & 4 & 0.00 & -1.86 & 0.07 & 2 & -0.01 & -2.49 & 0.32 & 2 & 0.00 & -2.18 & 0.10 & 1 & 0.00 & -0.74 & 0.37 \\
\hline Pulp, Paper and Printing & 32 & -0.03 & -2.67 & 0.11 & 7 & -0.03 & -1.26 & 0.19 & 13 & -0.03 & -2.16 & 0.09 & 7 & -0.04 & -1.01 & 0.20 \\
\hline Chemicals & -7 & 0.01 & 0.46 & 0.00 & 7 & -0.03 & -1.16 & 0.27 & -7 & 0.01 & 1.11 & 0.03 & -4 & 0.02 & 0.68 & 0.52 \\
\hline Non-Metallic Minerals & 7 & -0.01 & -0.78 & 0.01 & 12 & -0.05 & -3.01 & 0.23 & 11 & -0.02 & -2.15 & 0.09 & 8 & -0.04 & -1.66 & 0.56 \\
\hline Basic Metals & 14 & -0.01 & -0.77 & 0.01 & 21 & -0.08 & -2.87 & 0.33 & 22 & -0.04 & -2.82 & 0.15 & 13 & -0.08 & -2.16 & 0.66 \\
\hline Machinery & 6 & -0.01 & -1.44 & 0.03 & 1 & 0.00 & -0.65 & 0.14 & 8 & -0.02 & -3.93 & 0.25 & 4 & -0.02 & -2.10 & 0.64 \\
\hline Transport Equipment & 2 & 0.00 & -0.99 & 0.02 & 1 & -0.01 & -1.80 & 0.20 & 4 & -0.01 & -3.88 & 0.25 & 2 & -0.01 & -2.05 & 0.70 \\
\hline Non-Specified Industry & 14 & -0.01 & -1.77 & 0.05 & 12 & -0.05 & -3.49 & 0.29 & 10 & -0.02 & -2.44 & 0.11 & 6 & -0.04 & -1.71 & 0.50 \\
\hline Wholesale and Retail Trade & 11 & -0.01 & -1.26 & 0.03 & 4 & -0.02 & -1.04 & 0.22 & 18 & -0.03 & -2.38 & 0.11 & 15 & -0.09 & -2.30 & 0.57 \\
\hline Hotels and Restaurants & 1 & 0.00 & -0.24 & 0.00 & 1 & 0.00 & -0.56 & 0.28 & 0 & 0.00 & 0.03 & 0.00 & 0 & 0.00 & -0.23 & 0.34 \\
\hline Post and Telecommunications & 0 & 0.00 & -0.22 & 0.00 & 0 & 0.00 & 0.17 & 0.19 & 0 & 0.00 & -0.50 & 0.01 & 0 & 0.00 & -0.06 & 0.36 \\
\hline Financial Intermediation & 0 & 0.00 & 0.05 & 0.00 & 1 & 0.00 & -0.68 & 0.12 & -1 & 0.00 & 0.41 & 0.00 & 1 & 0.00 & -0.54 & 0.23 \\
\hline Renting, Computer, R\&D, Other Business & 3 & 0.00 & -0.97 & 0.02 & 3 & -0.01 & -1.92 & 0.26 & 6 & -0.01 & -2.80 & 0.15 & 3 & -0.02 & -2.07 & 0.62 \\
\hline Public Administration and Defense & 5 & 0.00 & -1.66 & 0.04 & 3 & -0.01 & -2.46 & 0.38 & 6 & -0.01 & -0.85 & 0.02 & 11 & -0.06 & -2.81 & 0.77 \\
\hline Education & 4 & 0.00 & -1.20 & 0.02 & 3 & -0.01 & -1.84 & 0.20 & 4 & -0.01 & -1.69 & 0.06 & 8 & -0.05 & -4.82 & 0.76 \\
\hline Health and Social Work & 1 & 0.00 & -0.17 & 0.00 & 2 & -0.01 & -0.84 & 0.21 & 1 & 0.00 & -0.15 & 0.00 & 5 & -0.03 & -2.69 & 0.82 \\
\hline Other Comm., Soc. \& Personal Services & 3 & 0.00 & -1.12 & 0.02 & 3 & -0.01 & -2.78 & 0.39 & 1 & 0.00 & -0.80 & 0.01 & 0 & 0.00 & 0.13 & 0.42 \\
\hline Total efficiency effect & 133 & -0.11 & -1.93 & 0.06 & 107 & -0.42 & -3.76 & 0.31 & 115 & -0.23 & -3.85 & 0.24 & 93 & -0.55 & -4.33 & 0.74 \\
\hline Total structure effect & -33 & 0.03 & 1.27 & 0.03 & -7 & 0.03 & 0.67 & 0.29 & -15 & 0.03 & 1.35 & 0.04 & 7 & -0.04 & -0.63 & 0.45 \\
\hline Aggregate energy intensity & 100 & -0.09 & -1.47 & 0.04 & 100 & -0.39 & -3.61 & 0.33 & 100 & -0.20 & -3.09 & 0.17 & 100 & -0.59 & -4.12 & 0.69 \\
\hline \# countries (cross section)* & & 11 & & & & 11 & & & & 18 & & & & 18 & & \\
\hline \# of observations* & & 61 & & & & 61 & & & & 48 & & & & 48 & & \\
\hline
\end{tabular}




\section{Conclusions}

Decreasing energy intensity (i.e., the ratio of energy input to economic activity) is crucial in addressing present-day concerns about greenhouse gas emissions and energy security. Both academic research and policy making in this area require insight in historic trends and determinants of this ratio, across countries and across sectors. Against this background we presented new stylized facts on energy intensity dynamics (both in terms of growth rates and levels) for 18 OECD countries and 50 sectors, during the period 19702005. Our analysis is based on a newly constructed database that combines the recently launched 'EU KLEMS Growth and Productivity Accounts' with physical energy data from the International Energy Agency (IEA). This dataset is unique in providing consistent high-quality and detailed data resources for a relatively long time span.

We found that across countries energy intensity levels tend to increase in a fairly wide range of Services subsectors, but decrease in most Manufacturing sectors. A considerable and increasing part of the observed aggregate energy intensity patterns is explained by changes in the sectoral composition of economies. Cross-country variation in aggregate energy intensity levels clearly tends to decrease since 1995 but not before. This pattern of convergence is driven by a remarkable strong and robust trend break towards convergence in Manufacturing, further enhanced by relatively strong convergence in Services. Across sectors lagging countries tend to catch-up with leading countries, with rates of convergence on average being higher in Services than in Manufacturing. Finally, we found that aggregate convergence patterns are almost exclusively caused by convergence of within-sector energy intensity levels, and not by convergence of the sectoral composition of economies.

We think these stylized facts can be fruitfully used for calibration of applied general equilibrium models and scenario analyses. Our dataset may be a valuable source of information for future empirical work in energy economics on the relationship between economic activity and energy use, also because its internal consistency facilities replication and comparability of studies across countries and across sectors. Future research along these lines may, for example, look into topics such as biased technology change, the estimation of production functions and production factor substitution elasticities, and the role of energy in economic growth processes.

\section{Appendix A. Supplementary data}

Supplementary data to this article can be found online at www.henridegroot.net. 


\section{References}

Abramovitz, M. (1986). 'Catching Up, Forging Ahead, and Falling Behind', Journal of Economic History, 47, pp. 385-406.

Abreu. M., R.J.G.M. Florax and H.L.F. de Groot (2005). 'A Meta-Analysis of Beta-Convergence: The Legendary Two-Percent', Journal of Economic Surveys, 19, pp. 389-420.

Aldy, J. (2006). 'Per Capita Carbon Dioxide Emissions: Convergence or Divergence?', Environmental and Resource Economics, 33, pp. 533-555.

Ang B.W., F.L. Liu and H. Chung (2004). 'A generalized Fisher index approach to energy decomposition analysis', Energy Economics, 26, pp. 757-763.

Ang, B.W. (2004). 'Decomposition for Policymaking in Energy: Which is the Preferred Method?', Energy Policy, 32, pp. 1131-1139.

Ang, B.W. and F.L. Liu (2001). 'A new energy decomposition method: perfect in decomposition and consistent in aggregation', Energy, 26, pp. 537-547.

Ang, B.W. and F.Q. Zhang (2000). 'A Survey of Index Decomposition Analysis in Energy and Environmental Studies', Energy, 25, pp. 1149-1176.

Ang, B.W., F.L. Liu and E.P. Chew (2003). 'Perfect decomposition techniques in energy and environmental analysis', Energy Policy, 31, pp. 1561-1566.

Barro, R.J. (1991). 'Economic Growth in a Cross-Section of Countries', Quarterly Journal of Economics, 106, pp. 407-443.

Barro, R.J. and X. Sala-i-Martin (1992). 'Convergence', Journal of Political Economy, 100, pp. 223-251.

Berndt, E.R. (1978). 'Aggregate Energy, Efficiency, and Productivity Measurement', Annual Review of Energy, 3, pp. $225-273$.

Boer, P. de (2009). 'Generalized Fisher index or Siegel-Shapley Decomposition?', Energy Economics, 31, pp. 810814.

Boyd, G.A. and J.M. Roop (2004). 'A note on the Fisher ideal index decomposition for structural change in energy intensity’, The Energy Journal, 25, pp. 87-101.

Cleveland C.J., R.K. Kaufmann and D.I. Stern (2000). 'Aggregation and the Role of Energy in the Economy', Ecological Economics 32, pp. 301-318.

Cornillie, J. and S. Fankhauser (2004). 'The energy intensity of transition countries', Energy Economics, 26, pp. 283-295.

Duro, J. A. and E. Padilla (2011). 'Inequality across countries in energy intensities: An analysis of the role of energy transformation and final energy consumption', Energy Economics, 33, pp. 474-479.

Eichhammer, W. and W. Mannsbart (1997). 'Industrial Energy Efficiency: Indicators for a European Cross-Country Comparison of Energy Efficiency in the Manufacturing Industry', Energy Policy, 25, pp. 759-772.

Fisher-Vanden, K., G.H. Jefferson, H.M. Liu and Q. Tao (2004). 'What's Driving China's Decline in Energy Intensity?', Resource and Energy Economics, 26, pp. 77-97.

Florax, R.J.G.M., H.L.F. de Groot and P. Mulder (2011). Improving Energy Efficiency through Technology: Trends, Investment Behaviour and Policy Design, Cheltenham: Edward Elgar. 
Gerschenkron, A. (1952). 'Economic Backwardness in Historical Perspective', in: B. Hoselitz (ed), The Progress of Underdeveloped Areas, University of Chicago: Chicago Press, pp. 5-30.

Grossman, G.M. and E. Helpman (1991). Innovation and Growth in the Global Economy, Cambridge MA: MIT Press.

Howarth, R.B., L. Schipper, P.A. Duerr and S. Strøm (1991). 'Manufacturing Energy Use in 8 OECD Countries', Energy Economics, 13, pp. 135-142.

Huntington, H.G. (2010). 'Structural Change and U.S. Energy Use: Recent Patterns', Energy Journal, 31, pp. 25-39. International Energy Agency (2004). Oil Crises and Climate Challenges - 30 Years of Energy Use in IEA Countries, Paris: OECD.

Islam, N. (1995). 'Growth Empirics: A Panel Data Approach', Quarterly Journal of Economics, 4, pp. 1127-1170.

Jakob, M., M. Haller, R.T. Marschinski (2012). 'Will history repeat itself? Economic convergence and convergence in energy use patterns', Energy Economics, 34, pp. 95-104.

Jorgenson, D.W. (1984). 'The Role of Energy in Productivity Growth', Energy Journal, 5, pp. 11-26.

Keller, W. (2002). 'Geographic Localization of International Technology Diffusion', American Economic Review, 92, pp. 120-142.

Lescaroux, F. (2008). 'Decomposition of US Manufacturing Energy Intensity and Elasticities of Components with espect to Energy Prices', Energy Economics, 30, pp. 1068-1080.

Liddle, B. (2009). 'Electricity Intensity Convergence in IEA/OECD Countries: Aggregate and Sectoral Analysis', Energy Policy, 37, pp. 1470-1478.

Liu, N. and B.W. Ang (2007). 'Factors Shaping Aggregate Energy Intensity Trend for Industry: Energy Intensity versus Product Mix’, Energy Economics, 29, pp. 609-635.

Ma, C. and D.I. Stern (2008). 'China's Changing Energy Intensity Trend: A Decomposition Analysis', Energy Economics, 30, pp. 1037-1053.

Mairet, N. and F. Decellas (2009). 'Determinants of Energy Demand in the French Service Sector: A Decomposition Analysis', Energy Policy, 37, pp. 2733-2744.

Markandya, A, A. Pedroso-Galinato and D. Streimikiene (2006). 'Energy Intensity in Transition Economies: Is There Convergence Towards the EU Average?', Energy Economics, 28, pp. 121-145.

Mendiluce, M., I. Pérez-Arriaga and C. Ocaña (2010). 'Comparison of the Evolution of Energy Intensity in Spain and in the EU15. Why is Spain Different?', Energy Policy, 38, pp. 639-645.

Metcalf, G. (2008). 'An Empirical Analysis of Energy Intensity and its Determinants at the State Level', Energy Journal, 29, pp. 1-26.

Miketa, A. (2001). 'Analysis of Energy Intensity Developments in Manufacturing Sectors in Industrialized and Developing Countries', Energy Policy, 29, pp. 769-775.

Miketa, A. and P. Mulder (2005). 'Energy-Productivity Across Developed and Developing Countries in 10 Manufacturing Sectors: Patterns of Growth and Convergence', Energy Economics, 27, pp. 429-453.

Mulder, P. (2005). The Economics of Technology Diffusion and Energy Efficiency, Cheltenham: Edgar Elgar.

Mulder, P. and H.L.F. de Groot (2007). 'Sectoral Energy- and Labour Productivity Convergence', Environmental and Resource Economics, 36, pp. 85-112. 
Mulder, P. and H.L.F. de Groot (2011). 'Energy Productivity Performance Across 14 OECD Countries: The Role of Energy-Extensive Sectors', in: R.J.G.M. Florax, H.L.F. de Groot and P. Mulder (eds), Improving Energy Efficiency through Technology: Trends, Investment Behaviour and Policy Design, Cheltenham: Edward Elgar, pp. 67-96.

Mulder, P., R. J.G.M. Florax and H. L.F. de Groot (2011). 'A spatial perspective on global energy productivity trends', in: R.J.G.M. Florax, H.L.F. de Groot and P. Mulder (eds), Improving Energy Efficiency through Technology: Trends, Investment Behaviour and Policy Design, Cheltenham: Edward Elgar, pp. 23-66.

Neelis, M.K., C.A. Ramírez, M.K. Patel, J. Farla, P. Boonekamp and K. Blok (2007). 'Energy Efficiency Developments in the Dutch Energy-Intensive Manufacturing Industry, 1980-2003', Energy Policy, 35, pp. 6112-6131.

Nilsson, L. (1993). 'Energy Intensity in 31 Industrial and Developing Countries 1950-88', Energy, 18, pp. 309-322.

O’Mahony, M. and M.P. Timmer (2009). 'Output, Input and Productivity Measures at the Industrial Level: The EU KLEMS Database', Economic Journal, 119, pp. F347-F403.

Park, S.H., B. Dissmann and K.Y. Nam (1993). 'A Cross-Country Decomposition Analysis of Manufacturing Energy Consumption', Energy, 18, pp. 843-858.

Quah, D. (1993). 'Galton's Fallacy and Test of the Convergence Hypothesis', Scandinavian Journal of Economics, 95, pp. 427-443.

Romero-Avila, D. (2008). 'Convergence in Carbon Dioxide Emissions Among Industrial Countries Revisited', Energy Economics, 30, pp. 2265-2282.

Schipper, L., F. Unander, S. Murtishaw and M. Ting (2001). 'Indicators of Energy Use and Carbon Emissions: Explaining the Energy Economy Link', Annual Review of Energy and Environment, 26, pp. 49-81.

Shapley, L.S. (1953). 'A value for n-person games', in: H. Kuhn and A.W. Tucker (eds), Contributions to the Theory of Games II, Princeton, NJ: Princeton University Press, pp. 307-317.

Siegel, I.H. (1945). 'The generalized “ideal” index-number formula', Journal of the American Statistical Association, 40, pp. 520-523.

Smulders, S. and M. de Nooij (2003). 'The Impact of Energy Conservation on Technology and Economic Growth', Resource and Energy Economics, 25, pp. 59-79.

Sue Wing, I. (2008). 'Explaining the Declining Energy Intensity of the U.S. Economy', Resource and Energy Economics, 30, pp. 21-49.

Sun, J. W. (2002). 'The decrease in the difference of energy intensities between OECD countries from 1971 to 1998', Energy Policy, 30, pp. 631-635.

Unander, F. (2007). 'Decomposition of manufacturing energy-use in IEA countries; How do recent developments compare with historical long-term trends?', Applied Energy, 84, pp. 771-780.

Unander, F., S. Karbuz, L. Schipper, M. Khrushch and M. Ting (1999). 'Manufacturing Energy Use in OECD Countries: Decomposition of Long Term Trends', Energy Policy, 27, pp. 769-778.

Wong, W. (2006). 'OECD convergence: A sectoral decomposition exercise', Economics Letters, 93, pp. 210-214.

Worrell, E. (2004). 'Industrial Energy Use, Status and Trends', Encyclopedia of Energy, pp. 395-406.

Zhang, F.Q. and B.W. Ang (2001). 'Methodological Issues in Cross-Country/Region Decomposition of Energy and Environmental Indicators', Energy Economics, 23, pp. 179-190. 